\title{
Analysis on the Manipulation of Securities Trading Behavior Prohibited by Law
}

\author{
Yu-fei XIA \\ The second Campus of North China Electric Power University \\ Baoding, Hebei, China
}

Keywords: Market Manipulation; Securities Trading; Illegal Behavior.

\begin{abstract}
Market manipulation is produced in the invisible, but has a profound and lasting influence on the national economy. In recent years, with the high prosperity and development of China's securities market, the illegal behavior of securities also poses a great challenge and threat to the stability of the securities market. In this paper, the author starts with the illegal behavior prohibited by the law of market manipulation, analyzes its definition, discriminates it from related concepts, produce background and development status, existing problems and countermeasures, and further explain the market manipulation behavior.
\end{abstract}

\section{Introduction}

In January 2017, Xu Xiang's handling of the market caused widespread concern in the capital market and was finally sentenced to $\$ 11$ billion and five years in prison for its manipulation of securities trading. This case once again triggered the illegal behavior of the community to manipulate the market, what is market manipulation? How can market manipulation be determined? What are the penalties for such violations in China's legal system? Through further analysis and discussion, the author believes that this illegal behavior will have a clearer and more accurate understanding.

\subsection{Overview of market manipulation}

The so-called manipulation of the market means that in securities trading, the actor uses the advantages of funds, stock holdings, information and other advantages to influence the price and quantity of securities trading, so as to occupy the dominant position of the securities market and obtain improper benefits. As the Chinese saying goes, "when water is clear, there is no fish", people often see the surface calm and ignore the deep crisis behind it. In the face of the different changes in the securities market, the vast number of small and medium-sized investors often blindly follow the trend of buying and selling, and do not study the driving factors behind it, and ultimately make the operator take advantage of the virtual and grab the benefits, but the investors pay irreparable price.

In view of the trend of polymorphism and continuous development of market manipulation, the theorists also have a variety of views on the classification of their types. The author thinks that market manipulation can be understood from the following four aspects: the first is information manipulation, which means investors manipulate by information superiority. Information-based manipulation also includes two situations: preemptive trading, which means that the operator intentionally creates information confusion, and the person who has the right to speak buys stocks and sells them after good news is known. The second aspect is transactional manipulation, which means that investors use false declarations, self-dealing, agreed transactions, continuous transactions, etc. The method interferes with the information in the securities market to influence the judgment and choice of investors. The third aspect is cross-market manipulation. The operator often trades in the futures market by manipulating the spot market price, and stealthily manipulates by the means of law evasion. The fourth aspect is specific time manipulation, which is mainly reflected in the opening bidding time or at the end of a certain time to manipulate, with its short period of time to quickly occupy the market position and profit. Generally speaking, market manipulation is a kind of fraudulent commercial behavior, which is also a great damage to the stability of the securities market. 
In the 1920s, the United States showed a boom in the financial sector, but people did not realize the "bubble economy" of false prosperity brought about by the long-term manipulation of the market by capitalists. Finally, the stock market crash became the trigger for the outbreak of economic crisis. The American economic crisis has alerted us to the fact that market manipulation is often imperceptible, but it has a profound and lasting impact on the national economy. Therefore, we need to strengthen the regulation of market manipulation in the securities trading activities, to prevent its adverse effects on the normal economic order, so as to ensure the smooth operation of the securities market.

\subsection{The distinction between market manipulation and "speculation"}

It is true that securities trading has the characteristics of risk and uncertainty, but this characteristic is based on a fair and orderly market order, if combined with the role of human factors, so not only to the interests of investors unjustified impairment, but also damage to the rules of operation of the market. Therefore, we should distinguish between market manipulation and normal "speculation".

Speculation can be divided into legal speculation and illegal speculation. The so-called legitimate speculation is that investors use the information they have through legitimate channels to carry out pre-judgment in order to carry out transactions that they subjectively consider beneficial to them. Such speculation will adjust the allocation of market resources. The redistribution of wealth, an active securities market has an important role in promoting. Unlike legitimate speculation, manipulation of the market manifests itself in the use of its own advantage of insider information to artificially influence the stock market, which violates the principle of fair competition and puts free competition under the control of individuals and capital. The illegal speculation is shown as a malicious speculation, although it can be called the important means to manipulate the market, but it can not be completely equated with the manipulation of the market.

As you can see, the most significant difference between market manipulation and market manipulation is that the manipulating the market, a trader's ultimate profit comes entirely from the trader's ability to change prices, not from its valuable information [1]. We do not exclude normal "speculation" in free trading in the stock market, but rather because investors make the best personal choices for their own interests. It is an important driving force for the development of securities industry. The distinction between market manipulation and speculation is made clear, and market manipulation relative to other trading firms is recognized. For the illegal, in order to further improve the relevant regulation of this kind of behavior.

\section{Background and Development of Market Manipulation}

\subsection{The emergence and development of market manipulation in the world}

Market manipulation, with the increasing frequency of securities trading, is becoming more and more diverse, which is driven by the interests of capital trading. The initial formation of the securities market can be traced back to Europe during the primitive accumulation of capitalism in the early 16th century. With the establishment of the world's first stock exchange in Amsterdam, the Netherlands in 1602, the stock exchange formally entered the historical stage. Early market manipulation was also hidden under the false appearance of capitalist prosperity. Up to now, with the financial securitization, the legalization of securities investment, the continuous development of the securities market network, the manipulation of the market has become increasingly diversified and technical. By setting up shell companies and high frequency trading, operators can influence the dynamics of the securities market invisibly. In the period of "Internet Big Bang" and "Information Big Bang", market manipulation also tends to be pluralistic, so it is urgent for all regulatory departments to strengthen relevant regulations in order to curb vicious competition behavior.

\subsection{The emergence and Development of China's Market manipulation}

The emergence of market manipulation in modern China can be said to be accompanied by the development of market economy. Under the highly centralized planned economy system in the early 
days of the founding of New China, China did not actually have the concept of "market", the securities industry had not taken root in China, and the manipulation of the market could not be traced back. Fundamentally speaking, it is the emergence of market manipulation. Since the reform and opening up, the development of the market economy has not only brought about a qualitative leap in China's economy, but also made money seem to be above everything else. Great changes have taken place in people's ideologies - "chasing profits", "going into business", "property speculation", "stock speculation". Such concepts have become common words in people's lives, and many market players attempt to gain benefits through vicious competition. Reflected in the stock market, a pair of profit-controlled hands behind the driving stock market prices, some people gain economic benefits, and some investors suddenly fell into the abyss of losses. In recent years, securities market manipulation cases have shown a high growth trend. In the first half of 2016 alone, 52 new market manipulation cases were set up by the CSRC, with a year-on-year growth rate of $68 \%$. In order not to repeat the 2008 economic crisis, the rights of the owners of the stock market are better protected. How to strengthen the supervision of market manipulation and punish this vicious competition by judicial means is worth our further exploration.

\subsection{The cognizance of manipulating the market and the responsibility of the CSRC}

Synthesizing the relevant laws and regulations in the practice of market manipulation, the identification of market manipulation should be considered from two aspects: first, subjective, that is, securities fraud exists in the subject. The deliberate behavior of manipulating the securities market, but in practice it is a normal transaction phenomenon to induce others to trade, so it is difficult to distinguish the illegal intention from the legal behavior. Then there is the objective aspect, that is, the behavioral subject objectively implements the manipulation of the securities market which may affect the transaction price and trading volume. But in practice, in order to avoid the legal risk and gain higher benefits, the manipulation of the market is often a long-term process, while the CSRC often focuses on the specific behavior in a specific period of time. Just as the regulation of anti-monopoly law in the field of economic law, the recognition of monopoly is often reflected in a monopoly state rather than monopoly behavior, and so should the recognition of market manipulation. The case of market manipulation by Xu Xiang mentioned at the beginning of the article is a typical systematic manipulation of the securities market. This "behind-the-scenes", "long-term" trading model often covers up the illegal practices of the operators. It is difficult to discern the man-made manipulation and the normal price fluctuation of the market, and many manipulators escape from it. Under the market background that the manipulation means are increasingly complex and the concealment is increasingly strengthened, the CSRC, as the function of centralized and unified supervision and administration of futures market, needs to bear more responsibility for the market supervision. At the internal management level, there is also an unreasonable human resource allocation, which is not relevant to the lack of market innovation. Therefore, we should strengthen the CSRC ' $\mathrm{s}$ centralized and unified supervision on the securities market, and pay attention to the self - discipline of the market subject, and rely on the self - discipline of the market subject. Law organizations, market organizations, intermediary service organizations form a self-discipline order to make up for the deficiencies in the regulatory process of the CSRC [1].

\section{The Judicialization of Market Manipulation}

Against the background of increasing market manipulation cases, we should also recognize the important mechanism of resolving disputes by legal means, and the judicial process of illegal market manipulation should be put on the agenda. In the legal system of our country, the administrative penalties and criminal sanctions for market manipulation are specified. Article 77 of the Securities Law also has only a concise provision: "if the manipulation of the securities market causes losses to investors, it shall bear civil liability for compensation according to law." The generalization of the generality of this provision should also be understood as the difficult problem behind it. The amount 
of compensation is difficult to determine, and the legal rules are not strict, which often will bring the certain difficulty to the actual operation. In this respect, we should extensively refer to the calculation methods of compensation amount in the United States, Singapore, Taiwan and other places. According to the characteristics of the development of our securities market, we should concretely implement the relevant damage compensation system so that it can follow the law.

We should also realize that one of the reasons why the illegal behavior of securities in our country is difficult to regulate is that the punishment for illegal behavior is less and the cost of illegal act is lower. On the issue of market manipulation, it is a good policy to properly carry out punitive damages to increase the illegal cost of relevant subjects. Compared with the commercial legal regulation in western countries, China has the characteristics of late start, slow development and incomplete regulation, which is closely related to the relevant economic system and economic background of our country. The speeding up of the judicial process of market manipulation should also be considered from the macroscopic system of commercial law of our country, which lies in the difference between civil and commercial relations, and should speed up the promotion of commercial code. In order to solve the problem of market manipulation, we can make up for the lack of macro-legal regulation in our country's commercial environment.

\section{The Protection of the Rights and Interests of Small and Medium-sized Investors Brought by Market Manipulation}

In the discussion of the topic of "democracy" in civil and commercial law, the principle of capital majority decision is an important voting mechanism of the relationship between civil and commercial, and the main body occupying the majority of capital will often use its dominant position to erode the rights and interests of a few capitalists. With the development and change of market economy, there is a trend of two-level differentiation between the commercial subjects, and the protection of the rights and interests of the small and medium-sized investors needs to be paid more attention to. In the process of market manipulation, it not only damages the normal economic order, but also challenges the smooth operation of the national economy. It also infringes on the equal participation of the small and medium-sized investors in the competition. From the characteristics of the infringement of market manipulation, this kind of tort is often the amount, the standard is huge, the infringement means presents a variety of situation, the infringed audience is also wide, and it is a large-scale form of tort. In the case of a single lawsuit, the interests of the weak people will be weakened further in the case of the imbalance of interests between the two sides.

For the protection of the rights and interests of small and medium-sized investors, the author thinks that the implementation should be carried out from the following aspects: first, in the level of investors' securities market access, we should improve the investor suitability system. Different investors adopt different investment standards, so that they can adapt to the qualification and competence of securities trading. Secondly, in the way of litigation, the majority of investors are the interest of the community, using representative litigation, the form of joint action, can make investors' rights and interests to be fully protected. As an important cell of the national economy and the ultimate victim of market operation, the protection of the interests of the small and medium-sized investors must also be obtained. Moreover, at the level of right relief for small and medium investors, we should perfect the compensation mechanism and adopt the centralized relief method to the small and medium investors. The relevant functional departments of the government should also strengthen the compensatory relief to the investors' losses caused by the weak supervision of the government, so as to protect the rights and interests of the small and medium-sized investors as much as possible. Finally, from the perspective of comparative law, Anglo-American law system countries as a pioneer of commercial development, the protection of the rights and interests of small and medium-sized investors is also in the forefront of the world. In the protection of investors' rights and interests, our country should draw lessons from the experiences of other countries and learn from foreign countries, for example, "Financial consumer rights and interests protection". The related theoretical basis of the 
nursing theory, as well as the institutional construction of the "Protection Center of the Rights and Interests of Small and Medium-sized Shareholders", strengthens the protection of the interests of small and medium-sized investors in a disadvantaged position in securities trading. The legislative purpose of protecting the legitimate rights and interests of investors in the Securities Law of China is put into practice.

\section{Conclusion}

The manipulation of the market constantly challenges the operator's own moral bottom line, and constantly impacts on the public, fair and just principles of the Securities Law of our country [3]. It has a great negative impact on the normal operation of the market mechanism. It is an inevitable requirement for the development of securities industry in China to establish and perfect the control system to manipulate the market. It is also an important guarantee for the smooth operation of the national economy.

\section{References}

[1] Zhang Pei-lun. Identification of Market manipulation and its Civil liability [J]. Beijing: Rule of Law Expo, 29 February 2016. (In Chinese)

[2] Deng Mingsong, Xu Qi. The manipulation Market of Securities Fraud Trading in China [J]. Beijing: Shang, 27 April 2016. (In Chinese)

[3] Wu Hong. A course in Securities Law [M]. Beijing: Peking University Press, August 2007. (In Chinese) 